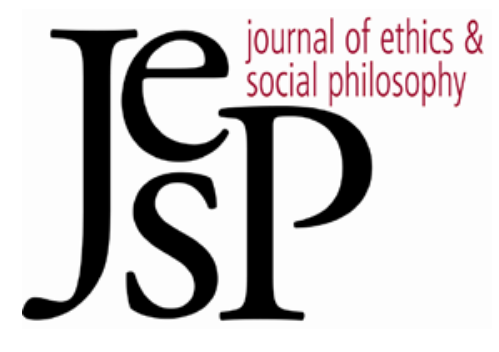

DISCUSSION NOTE

\title{
REASON TO PROMOTION INFERENCES
}

By Joshua DiPaolo and JefF Behrends

JOURNAL OF ETHICS \&SOCIAL PHILOSOPHY

Discussion Note | AUgUST 2015 URL: WWW.JESP.ORG COPYRIGHT @ JOSHUA DIPAOLO AND JEFF BEHRENDS 2015 


\title{
Reason to Promotion Inferences
}

\author{
Joshua DiPaolo and Jeff Behrends ${ }^{1}$
}

$\mathrm{H}$ UMEAN PROMOTIONALISM IS THE VIEW that there exists a reason for an agent to $\phi$ if and only if $\phi$-ing promotes one of her desires. Whether the promotion relation obtains, therefore, determines whether the reason relation obtains, on this view. One need not be a Humean, however, to think that promotion plays an important role in normative theory. Without claiming all reasons are desire-based reasons, anyone might accept that an agent has a desire-based reason to $\phi$ if and only if $\phi$ ing promotes one of her desires.

The promotion relation has recently come under scrutiny. Stephen Finlay (2006) and Mark Schroeder (2007) advance probabilistic accounts of promotion, on which an action promotes a desire just in case performing that action increases the probability of that desire. We argue elsewhere that Finlay's and Schroeder's probabilistic accounts fail: Increasing the probability of a desire is unnecessary for promotion because actions can promote desires even when the desire has probability 1 - a probability that cannot be increased (Behrends and DiPaolo 2011). D. Justin Coates (2014) proposes a new probabilistic account that, he argues, avoids our objections. Nathaniel Sharadin (2015) argues that Coates' proposal fails for a similar reason: Increasing the probability of a desire is unnecessary for promotion because actions can promote desires even when the desire has probability 0 - a probability that, according to Sharadin, cannot be increased. Sharadin then appeals to this conclusion to motivate his preferred account of the promotion relation.

We agree that Coates' proposal fails. ${ }^{2}$ However, we think that Sharadin's argument against Coates' view, and in favor of his own view, is flawed. The flaw suggests a modest methodological principle concerning inferences from reasons to promotion.

Roadmap: In $\int 1$, we explain Coates' proposal and Sharadin's argument against it. In $\int 2$, we identify the flaw in Sharadin's argument. In $\int 3$, we discuss the methodological upshot.

\section{A New Account and an Alleged Problem}

Probabilistic accounts need to answer the Baseline Question: The action increases the probability of the desire relative to what? Finlay's and Schroeder's

\footnotetext{
1 We have adopted the convention of alternating the order in which our names appear on co-written papers. This paper is the product of full and equal contribution between its authors.

2 We argue for this in Behrends and DiPaolo (unpublished).
} 
answers are problematic, so defenders of probabilistic accounts need a different answer. ${ }^{3}$

Coates suggests that Finlay's and Schroeder's accounts fail because they allow for extrinsic factors to determine the probabilities. In short, Coates recommends understanding promotion in terms of "antecedent intrinsic probabilities" (AIPs). A fair die, Coates claims, has a 1/6 AIP of coming up 3 , even if God would make it come up 3 every time it is rolled. An action promotes a desire, on Coates' view, just in case the agent's performing the action makes the probability of the desire greater than its AIP. Following Sharadin, we can state Coates' view as follows:

Coates-Promote: A-ing promotes D iff $\operatorname{pr}(\mathrm{D} \mid \mathrm{A})>\operatorname{pr}_{I}(\mathrm{D})$ letting $p r_{I}(\bullet)$ be the AIP function.

Sharadin argues that Coates-Promote fails because some desires, D, are such that $\operatorname{pr}_{I}(\mathrm{D})=0$ and these desires can be promoted. If true, these claims would show that increasing the probability of D relative to its AIP is unnecessary for promotion. Sharadin (2015: 1379) appeals to two examples to defend these claims:

Consider again the desire to lack any desires at all. Suppose an agent has this desire and is offered the opportunity to undergo extensive Buddhist training, which she has good reason to believe will lead to a reduction in the number of desires she has. Intuitively, there is a reason for the agent to undergo the training. And this is so because undergoing the training promotes her desire to lack any desires at all.

...

Or consider a desire with infinitary content, such as the desire to live forever... Suppose an agent desires to live forever and is offered a pill that will extend her life by a thousand years. The agent has a reason to take the pill. And this is so because taking the pill promotes her desire to live forever.

Call the agent in question "Agatha." Let $D_{1}$ be Agatha's desire that she lacks any desires at all, and let $D_{2}$ be her desire that she lives forever. According to Sharadin, $\operatorname{pr}_{I}\left(\mathrm{D}_{1}\right)=\operatorname{pr}_{I}\left(\mathrm{D}_{2}\right)=0$, and no course of action can increase the probabilities of these desires. We will suppose this is correct.4 It follows from

${ }^{3}$ In this paper, we focus on Coates' probabilistic account and Sharadin's response to it. Addressing other accounts (e.g., those in Finlay 2014 and Snedegar 2014) is beyond the scope of this paper.

${ }^{4}$ We grant this for the sake of argument. (After this note, we ignore issues involving Coates' notion of AIPs, and Sharadin's formalization of Coates-Promote. Putting our cards on the table: We think that both are problematic. We elaborate on this claim in Behrends and DiPaolo (unpublished).) Whether the supposition in the text is correct depends on how exactly Coates' account should be understood. One might find the following argument tempting: Although the probability of water turning into wine has an AIP of 0 , conditional on certain factors the probability of this happening is greater than 0 , so Coates-Promote allows for promotion of desires whose content has an AIP of 0 . But, in elucidating the concept of an AIP, Coates (2014: 5) argues that, if there is a possible world in which P obtains, its AIP is greater than 0 . So this example will not show that desires with contents having an AIP of 0 
Coates-Promote that no course of action could promote these desires. Yet, Sharadin argues, undergoing the training promotes $\mathrm{D}_{1}$ and taking the pill promotes $\mathrm{D}_{2}$. So, Coates-Promote fails.

Sharadin recommends, instead, a disjunctive account of promotion, in terms of either probability raising or increase in fit between the desire's content and the world. If Julie has three bars of chocolate, but desires to have six, then obtaining another bar promotes her desire because the world in which Julie has four fits her desire better than the world in which she has three; obtaining a fourth bar increases the fit between her desire and the world, according to Sharadin (2015: 1380). This disjunctive account, he argues, is preferable to Coates-Promote because it can explain why undergoing the Buddhist training promotes $\mathrm{D}_{1}$. Sharadin (2015: 1382) explains, "the world where you have, say, 499 desires (as a result of undergoing the training) better fits the world picked out by your desire than the actual world where you have, say, 511 desires." ${ }_{5}$ Whether or not undergoing the training promotes $\mathrm{D}_{1}$, we will take it for granted that it increases the fit between the world and $\mathrm{D}_{1}$.

\section{The Flaw in the Argument}

Sharadin's key premise is that some actions promote the satisfaction of desires with intrinsic probability 0 even though these actions never make the satisfaction of the desire more likely. His examples are meant to justify these more specific claims:

$\mathrm{H}_{1}$ : Undergoing the training promotes $\mathrm{D}_{1}$. $\mathrm{H}_{2}$ : Taking the pill promotes $\mathrm{D}_{2}$.

How do they justify these claims?

According to Sharadin, in each case there is a reason to perform some action because performing that action promotes $\mathrm{D}_{1}$ or $\mathrm{D}_{2}$. Recall:

- "Intuitively, there is a reason for the agent to undergo the training. And this is so because undergoing the training promotes her desire to lack any desires at all."

can be promoted because, assuming it is possible for water to turn into wine, this content does not have an AIP of 0 . An example of something with an AIP of 0 might be a fair, sixsided die coming up 7; presumably, no matter what we conditionalize on, the probability of this will always be 0 . And Sharadin explicitly asserts that "no amount of conditionalization" could move the probability of the desires in his cases from 0 (2015: 1379). That being said, if this supposition is wrong, Sharadin's argument does not get off the ground; yet, because we find the notion of an AIP unclear, we are willing to grant Sharadin this claim to show that, even if it is correct, his argument still fails. We are grateful to an anonymous reviewer for urging us to clarify our position here, and for supplying the water-into-wine example.

5 Sharadin appeals only to quantitative examples to motivate and explain this notion of "increase in fit." What he says about those cases seems questionable, but this notion will be even more difficult to apply (and the theory that much more difficult to assess) when the desires are nonquantitative. We set this worry aside, though, in what follows. 
- "The agent has a reason to take the pill. And this is so because taking the pill promotes her desire to live forever."6

Notice the inference is not of this form:

\section{General}

1. There is a reason for $\mathrm{S}$ to $\phi$.

2. Therefore, $\phi$-ing promotes some desire $\mathrm{S}$ has.

This inference goes from a general existential reason claim to a general existential desire claim. Sharadin's inference has the following form:

\section{Particular}

1. There is a reason for $\mathrm{S}$ to $\phi$.

3. Therefore, $\phi$-ing promotes S's desire D.

This inference, a particular reason-to-promotion inference, goes from a general existential reason claim to a claim about an action's promoting a particular desire. Assuming Humean Promotionalism as a suppressed premise, General is a deductively valid inference. However, even given Humean Promotionalism, Particular is an invalid inference. It does not follow, however, that Particular is never a good inference. Not all good inferences are deductively valid.7

One way to make a good Particular reason-to-promotion inference is to show that the particular desire's promotion is the best explanation of the reason, given the background information. That is how we should conceive of Sharadin's argument. Given the background information and that the agent has a reason to $\phi$, the best explanation of this data is that $\phi$-ing promotes the agent's desire that $\mathrm{D}$.

6 Sharadin's language might suggest that we are mischaracterizing the inference. After all, don't we teach our critical thinking students that "because" is a premise indicator? In which case, the claim that undergoing training promotes Agatha's desire to lack any desires is a premise supporting the claim that she has a reason to undergo training. Even if the language suggests this, it is not how the inference works. The "because" indicates the explanans of an inference to the best explanation (see below). Recall what Sharadin is trying to show: Some actions promote the satisfaction of desires with AIP 0 even though those actions do not increase the probability of the desire. The promotion claim is part of his conclusion. The only work done by the reason claim is that it justifies the promotion claim. In this argumentative context, there would be no reason to make the reason claim if it were not justifying the promotion claim.

${ }^{7}$ Another interpretive concern one might have is that we have mischaracterized Sharadin as making an inference at all at this stage of his argument, rather than merely relying on a kind of direct intuition that $\phi$-ing promotes the desires in question. In personal correspondence, though, Sharadin has confirmed that we have indeed characterized his reasoning correctly. Further, we address below what to make of the judgment that $\phi$-ing promotes $\mathrm{D}_{1}$ and $\mathrm{D}_{2}$, once those desires are disentangled from related desires. We are grateful to an anonymous reviewer for urging us to further consider our interpretation of Sharadin's reasoning, and to Sharadin himself for allowing us to cite our correspondence here. 
Nevertheless, Sharadin's arguments for $\mathrm{H}_{1}$ and $\mathrm{H}_{2}$ are unpersuasive. In the first case, there may be a reason for Agatha to undergo training. But this does not show that undergoing training promotes her desire to lack any desires at all. She may have another desire that undergoing the training would promote, and this desire-promotion relationship may ground her reason to undergo training.

For instance, suppose that Agatha knows that she has many desires and she knows that she must have fewer desires to have no desires. As a result, she likely desires to have fewer desires. Undergoing the training would promote this desire because it would satisfy it. Thus, we can explain why Agatha has a reason to undergo training without claiming that undergoing the training promotes $\mathrm{D}_{1} \cdot{ }^{8}$

Now suppose that Agatha does not desire to have fewer desires; the only desire she has related to the Buddhist training is her desire to lack any desires. Or, suppose that, in addition to this desire, she has the conditional desire to have many desires if she must have any. Either way, it is not obvious that she has a desire-based reason to undergo training. When she has the conditional desire, she has a reason not to undergo the training - the training will do the opposite of promote this desire. This is consistent with her also having a reason to undergo the training, of course. But it is not obvious that she has a desire-based reason to undergo the training.

So, when we suppose that Agatha has other desires that would clearly be promoted by undergoing the training, it seems obvious that she has a reason to undergo the training; when we suppose that the only desire relevant to the training is her desire to lack all desires, it does not seem obvious that she has a reason to undergo the training. The best explanation of the claim that she has a reason to undergo the training in the original case, then, arguably is not that doing so promotes her desire to lack all desires. Rather, it is that some desire in the neighborbood of that desire would be promoted by undergoing the training.

Before clarifying this neighborhood notion, we will show that the same sort of response applies to the second case. If Agatha desires to live forever, she probably also has other desires related to this desire that would be promoted by her taking the pill, like the desire to live for another thousand years. If she has this desire, then she would clearly have a reason to take the pill, since taking the pill would clearly promote this desire. If, on the other hand, the only desire Agatha has that would be related to taking the pill is her desire to live forever, then it is not obvious that she has a desire-based reason to take the pill.

Sharadin offers more defense of his verdict in this case. But this defense is not compelling. First, he claims that, if she lacked the desire, she might not

8 See Finlay (2014: 153-54) for a discussion of similar sorts of cases, and for Finlay's preferred treatment of them in terms of preference scales of multiple individual ends. We are grateful to an anonymous reviewer for drawing our attention to Finlay's discussion. 
have a reason to take the pill. This is true, but it does not support $\mathrm{H}_{2}$ over the hypothesis that taking the pill promotes Agatha's desire to live another thousand years. She might not have a reason to take the pill, but if she still has this desire, she would have a reason to do so. And if lacking $\mathrm{D}_{2}$ means that she also lacks this desire (and all other desires in the neighborhood), then she does not have a desire-based reason to take the pill. But this does not favor $\mathrm{H}_{2}$ over the alternative hypothesis.

Second, he claims that if Agatha has some other desire, like the desire to live only the next 500 years, she might have a positive reason not to take the pill. Call the desire to live another thousand years $\mathrm{D}_{3}$ and the desire to live only the next 500 years $\mathrm{D}_{4}$. There are several cases to consider. If Agatha has all of $\mathrm{D}_{2}-\mathrm{D}_{4}$, she might have positive reason not to take the pill, but this does not show that she does not also have a reason to take the pill. Agents can simultaneously have reasons to $\phi$ and reasons not to $\phi$. In another case, Agatha has only $\mathrm{D}_{3}$ and $\mathrm{D}_{4}$. Again, it seems like she has a desire-based reason to take the pill (grounded in $\mathrm{D}_{3}$ ) and a desire-based reason not to take the pill (grounded in $\mathrm{D}_{4}$ ). Notice, in the absence of $\mathrm{D}_{2}$, that Agatha still has a reason to take the pill. Finally, if Agatha has only $\mathrm{D}_{4}$, she probably will not have a reason to take the pill. But this does not support $\mathrm{H}_{2}$ over the alternative hypothesis.

Thus, we suggest that Sharadin's argument for the claim that actions can promote the satisfaction of desires with AIP 0 does not succeed. It fails to take into account desires in the neighborhood of those desires. When we account for these desires, it is more plausible to suppose either that these desires are what the actions promote or that the actions do not promote any of the agent's desires. ${ }^{9}$ Moreover, if this is correct, and if Sharadin's disjunctive account implies, as he claims it does, that undergoing the training promotes $\mathrm{D}_{1}$, then that account gets the wrong results. ${ }^{10}$

\section{Methodological Upshot}

The notion of desires in the neighborhood of other desires is intuitive, we think, but it is bound to be vague. Nevertheless, the following seem to be plausible sufficient conditions for one desire, D, being in the neighborhood of another desire $\mathrm{D}^{\prime}$ :

- It is probable that $\mathrm{S}$ has $\mathrm{D}$ if she has $\mathrm{D}^{\prime}$.

- Having D is constitutive of having $\mathrm{D}^{\prime}$.

\footnotetext{
${ }^{9}$ In unpublished work developed subsequent to the writing of this paper, Eden Lin advances a similar objection.

10 Two points. First, we contend that the same objection applies to the Julie/chocolate bar example above. Second, Sharadin's account could avoid getting the wrong results by denying what Sharadin claims - namely, that undergoing the training increases the fit between $\mathrm{D}_{1}$ and the world. If we deny that claim, then the disjunctive account turns out to be unmotivated. Either way, we are left without good reason to adopt the account.
} 
- It is necessary that $\mathrm{S}$ has $\mathrm{D}$ if she has $\mathrm{D}^{\prime}$.

- A rational agent has $\mathrm{D}^{\prime}$ only if she has $\mathrm{D}$.

- S's having D is (partially) explained by S's having D'.

- There is some set of propositions $\{\mathrm{P}, \mathrm{Q}, \ldots\}$ that is entailed by the propositional contents of both D and D'.

Although this list is not exhaustive and these statements probably require some tinkering, we think they help clarify the notion.

Call $\mathrm{H}_{1}$ and $\mathrm{H}_{2}$ initial hypotheses, simply because they are hypotheses someone (Sharadin, in this case) is initially inclined to infer from reason claims. And call the hypotheses that undergoing training promotes Agatha's desire to have fewer desires and that taking the pill promotes Agatha's desire to live another thousand years neighborhood hypotheses. They are neighborhood hypotheses because (i) they are alternatives to the initial hypotheses and (ii) they involve desires in the neighborhood of the desires in the initial hypotheses. Given this terminology, we suggest the following modest methodological principle concerning reason-to-promotion inferences:

\section{Check the Neighborhood}

Before making a Particular reason-to-promotion inference, consider neighborhood hypotheses. If a neighborhood hypothesis is as good an explanation of the reason as the initial hypothesis, do not make this inference.

This principle does not imply that we should never conclude that a particular course of action promotes a particular desire. Rather, it simply suggests that we need more evidence in favor of the promotion claim to reach this conclusion, beyond the fact that the reason's existence can be explained by that particular promotion claim.

Now, we are not suggesting that Sharadin has committed some novel kind of fallacy in violating Check the Neighborhood. However, we do think that formulating the principle in the way that we have here could be helpful. Check the Neighborhood goes beyond simply reminding us to pay attention to the contents of the relevant desires when thinking about desire-based reasons, or to consider alternative explanations when making inferences to the best explanation. It does remind us of these things, but in addition to advancing such general exhortations, it warns us of a particular mistake we might make when performing a specific kind of inference to the best explanation, and, by indicating specific alternative hypotheses to consider, it provides some guidance about how to avoid making this mistake. This difference parallels the difference between (e.g.) advancing the general imperative "Do not forget to pack everything you need" and providing a checklist of what to pack, or between (e.g.) offering the general recommendation "Stick to the path" and warning of common points at which one might naturally stray from the path.

Given the recent increased attention to promotion, it is important that we follow the principle's advice now, to avoid pursuing unmotivated ac- 
counts of promotion. Sharadin uses his diagnosis of Agatha's cases to argue against Coates' account of promotion and to motivate his own disjunctive account. However, if our arguments succeed, his argument against Coates' account is unsound and his own account turns out to be unmotivated, and probably false. Checking the neighborhood would have been helpful in this case, we think, and may help us avoid other unmotivated trails in the future.11

Joshua DiPaolo

University of Massachusetts

Department of Philosophy

jdipaolo@philos.umass.edu

Jeff Behrends

Illinois State University

Department of Philosophy

jmbehre@ilstu.edu

${ }^{11}$ We thank Nathaniel Sharadin and an anonymous reviewer for reading and commenting on an earlier version of this paper, and Gina Schouten for discussion. DiPaolo's work on this paper was made possible through the support of a grant from the John Templeton Foundation. The opinions expressed in this publication are those of the authors and do not necessarily reflect the views of the John Templeton Foundation. He would also like to thank Saint Louis University, and its Department of Philosophy, for their funding and support. 


\section{References}

Behrends, J. and DiPaolo, J. (2011) "Finlay and Schroeder on Promoting a Desire," Journal of Ethics and Social Philosophy 6: 1-6.

(unpublished) "Probabilistic Promotion Revisited."

Coates, D. J. (2014) “An Actual-Sequence Theory of Promotion," Journal of Ethics and Social Philosophy 8: 1-7.

Finlay, S. (2014) Confusion of Tongues: A Theory of Normative Language, Oxford: Oxford University Press.

(2006) “The Reasons That Matter," Australasian Journal of Philosophy 84(1): 1-20.

Lin, E. (unpublished) "Simple Probabilistic Promotion."

Schroeder, M. (2007) Slaves of the Passions, Oxford: Oxford University Press.

Sharadin, N. (2015) "Problems for Pure Probabilism about Promotion (and a Disjunctive Alternative)," Philosophical Studies 172(5): 1371-86.

Snedegar, J. (2014) “Contrastive Reasons and Promotion,” Ethics 125(1): 39-63. 